\title{
LEOPOLDO CALVO-SOTELO Y LA BATALLA POR TELEVISIÓN ESPAÑOLA (1981-1982)
}

\author{
LEOPOLDO CALVO-SOTELO AND THE BATTLE \\ FOR TELEVISION (1981-1982)
}

José-Vidal Pelaz López*

Universidad de Valladolid, España

\begin{abstract}
RESUMEN: El objetivo de este artículo es analizar la política del Gobierno de Leopoldo CalvoSotelo con respecto a la televisión entre 1981 y 1982. Para ello se utilizan testimonios de protagonistas, prensa de la época y archivos personales (principalmente el del propio Calvo-Sotelo). Se estudia la evolución de RTVE a lo largo de los mandatos de los tres directores que tuvo en estos años: Fernando Castedo, Carlos Robles Piquer y Eugenio Nasarre. Su trayectoria estuvo marcada por las constantes denuncias de manipulación de que fueron objeto y que provocó el cese de los dos primeros en medio de una gran polémica pública. Paralelamente a la críticas sobre el uso partidista de la Televisión pública el Gobierno intentó legalizar la televisión privada, lo que no consiguió, en buena medida debido a las disputas internas de UCD. La principal conclusión de este estudio es que la situación de la televisión constituyó un elemento clave en el debate político entre gobierno y oposición y que fue un factor fundamental en el deterioro de la imagen del presidente Calvo-Sotelo, y en último término, en el desgaste de UCD.
\end{abstract}

PALABRAS CLAVE: Transición española; Leopoldo Calvo-Sotelo; UCD; Televisión española; televisión privada.

ABSTRACT: The aim of this paper is to analyze the politics of the Government of Leopoldo Calvo-Sotelo towards the television between 1981 and 1982. We use protagonists' testimonies, press, and personal records (principally from Calvo-Sotelo Archive). RTVE's evolution is studied along the mandates of the three directors in these years: Fernando Castedo, Carlos Robles Piquer y Eugenio Nasarre. Their mandates were determined by constant allegations of manipulation and provoked the dismissal of both first ones mired in controversy. In parallel to critiques on the partisan use of the public Television the Government tried to legalize the private television, which it did not obtain, mostly due to UCD's internal disputes. The main conclusion of this study is that the situation of the television constituted a key element in the political debate between government and opposition and that was a fundamental factor in the deterioration of the president Calvo-Sotelo's public image, and in last term, in UCD's wear.

KEYWORDS: Spanish transition; Leopoldo Calvo-Sotelo; UCD; Spanish television; private television

* Correspondencia a: José-Vidal Pelaz López, Departamento de Historia Moderna, Contemporánea, América, Periodismo, Comunicación audiovisual y Publicidad, Facultad de Filosofía y Letras, Universidad de Valladolid. (España). Plaza del Campus s/n, Valladolid, 47011 - pelaz@fyl.uva.es - https://orcid.org/0000-0001-7255-4430.

Cómo citar: Pelaz López, José-Vidal (2019). «Leopoldo Calvo-Sotelo y la batalla por Televisión Española (1981-1982)»; Historia Contemporánea, 61, 1005-1037. (https://doi.org/10.1387/hc.19548).

Recibido: 11 abril, 2018; aceptado: 23 agosto, 2018.

ISSN 1130-2402 - eISSN 2340-0277 / (C) 2019 UPV/EHU

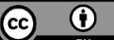

Esta obra está bajo una licencia

Creative Commons Atribución 4.0 Internacional 


\section{Introducción}

Desde el momento en que accedió a la presidencia del gobierno en febrero de 1981, la televisión se convirtió en un problema para Leopoldo Calvo-Sotelo. En primer lugar, porque la utilización de la pequeña pantalla por parte de su antecesor había sentado un peligroso precedente, al convertir la telegenia en una poderosa arma política. En segundo término, porque la aprobación del Estatuto de Radio Televisión Española por consenso entre UCD y PSOE en 1980, había cambiado las reglas del juego. Ahora la televisión pública estaba sometida a un Consejo de administración con representación proporcional a la parlamentaria y las Cortes fiscalizaban su gestión. Además, la propia figura del nuevo director general Fernando Castedo despertaba recelos entre los miembros de UCD, porque algunos lo consideraban demasiado proclive a simpatizar con la izquierda. Y, por último, estaba la cuestión de la televisión privada, sobre la cual había dentro de UCD serias discrepancias, mientras que la izquierda se oponía frontalmente.

En este contexto la política de Calvo-Sotelo estuvo dominada por las dudas y las vacilaciones. Si utilizaba demasiado la televisión (como hiciera Suárez) las acusaciones de manipulación se dispararían. Si mantenía a Castedo como director general, cargarían contra él los democristianos de UCD. Si lo sustituía (lo que ocurrió pocos meses después), ocurriría lo propio con socialdemócratas y suaristas. Y si autorizaba la televisión privada, la oposición de izquierda se le pondría frontalmente en contra y corría el riesgo de dividir aun más a su propio partido.

Como ocurre con otros muchos aspectos de la etapa de gobierno de Leopoldo Calvo-Sotelo, este tema ha sido escasamente atendido por los historiadores tanto de la política como de la comunicación ${ }^{1}$. Ante la ausencia de una monografía sobre esta breve pero intensa fase de la Transición, no son muchas las referencias sobre la política televisiva que se pueden rastrear en los trabajos de Charles Powell, Álvaro Soto o Carlos Barrera, ni en las obras sobre UCD de Carlos Hunneus, Silvia Alonso Castrillo o Jonathan Hopkin ${ }^{2}$. Algo similar ocurre en los estudios sobre la televisión durante la Transición. El deslumbrante uso de la pequeña 2018 .

${ }_{1}^{1}$ Un balance historiográfico sobre el mandato de Calvo-Sotelo en Pelaz y Díez,

2 Powell, 2002; Soto, 2005; Barrera, 2002; Hunneus, 1985; Alonso Castrillo, 1996; Hopkin, 2000. 
pantalla por parte de Adolfo Suárez, estudiado por Virginia Martín Jiménez, ha eclipsado los problemas que tuvo luego su sucesor ${ }^{3}$. Los expertos, quizá con la excepción de Nuria Quintana, prefieren centrarse más en lo relativo a la programación que en las batallas políticas que sacudieron al ente: es lo que podemos ver en los trabajos de Palacio (que apenas dedica unas líneas a Calvo-Sotelo), de Rueda y Chicharro, Bustamante o en la monumental obra coordinada por Julio Montero ${ }^{4}$. Ante la ausencia de trabajos históricos, se hace necesario recurrir a los de origen periodístico, como el de Pérez Ornia (si bien esta etapa la toca de forma muy secundaria), Munsó Cabús o, sobre todo, Justino Sinova, que hace un relato ordenado de las relaciones de la televisión con el poder desde 1977 verdaderamente estimable, y Eduardo Sotillos, actor destacado en aquellos momentos ${ }^{5}$. Contamos también con los testimonios de los protagonistas para aproximarnos a la cuestión, en primer lugar las memorias del propio Calvo-Sotelo (fuente inestimable a pesar de su obvia subjetividad) y luego las aportaciones de Miguel Herrero, Alfonso Guerra, Julio Feo, Fernando Castedo, Manuel Fraga, Carlos Robles Piquer, Emilio Attard, Matías Rodríguez Inciarte y Eugenio Nasarre, entre otros $^{6}$. Estos dos últimos, además, han sido entrevistados para este artículo con cierta profundidad.

Sobre esta base la aportación más original de este trabajo reside en un conjunto de documentación inédita procedente del archivo privado de Leopoldo Calvo-Sotelo. Cartas, informes reservados, encuestas del CIS, discursos o textos del propio presidente sustentan en lo fundamental esta investigación. Este material se ha visto complementado con las informaciones de prensa, fundamentales para evaluar el impacto social y político de los vaivenes en la cúpula de RTVE, muchas de ellas procedentes de la propia hemeroteca presidencial, completadas con la consulta a las colecciones de $A B C$, Diario 16 y El País. De forma subsidiaria se ha utilizado también material del archivo de José Pedro Pérez Llorca (para

3 Martín Jiménez, 2013.

${ }^{4}$ Quintana, 2007; Palacio, 2012; Rueda y Chicharro, 2006; Bustamante, 2006; Montero, 2018.

5 Pérez Ornia, 1988; Munsó, 2001; Sinova, 1983; Sotillos, 2002.

${ }^{6}$ Calvo-Sotelo, 1990; Calvo-Sotelo Ibáñez Martín, 2010; Herrero, 1993; Guerra, 2007; Feo, 1993; Castedo, 1984; Fraga, 1987; Robles Piquer, 2011; Attard, 1983; Rodríguez Inciarte, 1984 y Nasarre, 1984. 
aclarar el nombramiento de Robles Piquer $)^{7}$, y de José Antonio Pérez González (sobre la actitud de Suárez con respecto a Castedo) ${ }^{8}$.

Los ejes centrales de este trabajo son el estudio de las relaciones del presidente del Gobierno con los diferentes directores generales de RTVE, la crítica ejercida desde la prensa ante el control gubernamental del medio televisivo y la actitud ante todo ello de la oposición y de los propios miembros de UCD. El objetivo último es desentrañar que papel desempeñó en esta etapa final de la Transición la lucha feroz desatada entorno a la televisión, y como contribuyó al descrédito del Gobierno, a la división del partido y, en último término, al menoscabo de la propia figura del presidente. Todo parece indicar que el control de Televisión Española por parte de UCD fue un arma de doble filo porque enconó la pugna interna dentro del partido gubernamental, a la vez que los socialistas convertían las críticas al medio en un instrumento decisivo para lograr el desgaste del ejecutivo.

\section{Castedo: una herencia envenenada}

Cuando el 28 de mayo de 1980 Alfonso Guerra subió a la tribuna del Congreso para justificar la presentación de una moción de censura contra el gobierno de Adolfo Suarez, lo primero que hizo fue denunciar que el Gobierno utilizaba «la televisión, para falsear la verdad sobre este acontecimiento parlamentario». A continuación explicó que «el despilfarro, la arbitrariedad frente a las leyes y la incompetencia campan por sus respetos en Radio Televisión Española» ${ }^{9}$. Poco antes el PSOE había presentado una querella criminal, firmada entre otros por Felipe González y el propio Guerra, contra los dos últimos directores de Televisión. No cabe duda de que RTVE se había colocado en el centro del debate político nacional.

7 Archivo General de la Universidad de Navarra (en adelante AGUN), José Pedro Pérez Llorca (en adelante JPPL), 263/033. Documentación disponible gracias a la amabilidad de Gema Pérez Herrera, autora de una Tesis Doctoral sobre la trayectoria política de Pérez Llorca, Pérez, 2017.

${ }^{8}$ Información obtenida gracias a la amabilidad de Darío Díez Miguel, autor de una Tesis doctoral sobre el CDS, Díez Miguel, 2017.

9 Diario de Sesiones del Congreso de los Diputados, n. ${ }^{\circ} 93,28-5-1980$, pp. 6083 y ss. Guerra, 2007, p. 358. Pérez Ornia, 1988. 
En los meses siguientes UCD y PSOE acordaron que el primer director del Ente (creado desde enero de 1980), fuera el abogado del estado Fernando Castedo, hombre de confianza de Pío Cabanillas, y entonces secretario del Instituto de Cooperación Iberoamericana ${ }^{10}$. El nombramiento de Castedo el 9 de enero de 1981 por el consejo de administración de RTVE, que para algunos «constituyó otra prueba irrefutable de la debilidad mostrada por los dos últimos gobiernos de UCD» ${ }^{11}$, fue saludado por otros como el inicio de una nueva era ${ }^{12}$. Había un notable consenso en la prensa sobre sus retos: conseguir la neutralidad política, mejorar la situación económica, redimensionar la plantilla, elevar la calidad de la programación, acabar con la censura. En síntesis, como apuntaba El País, una «drástica ruptura del búnker de incompetentes, vagos o corruptos que han degradado el monopolio estatal» ${ }^{13}$.

Apenas unos días después se producía la dimisión de Adolfo Suárez y la designación de Leopoldo Calvo-Sotelo. Este conocía a Castedo desde 1977, en que se ocupó de los asuntos jurídicos de la campaña, pero no parece que la relación fuera muy cercana ${ }^{14}$. Solo habían pasado unas pocas semanas desde su llegada a Prado del Rey y en UCD ya había preocupación por su inquietante orientación izquierdista. Entre los informes recabados por Calvo-Sotelo para preparar su discurso de investidura se conserva uno al respecto particularmente demoledor. En él se explicaba como la primera decisión de Castedo había sido nombrar a «personas afectas a la izquierda» sin contar con los miembros de UCD en el Consejo, aduciendo

como último argumento el de que los nombramientos los había despachado con el Ministro Cabanillas y con el Presidente del Gobierno y

10 Sinova, 1983 , pp. 46 y ss.

11 Munsó, 2001, p. 166.

12 El Consejo se había constituido el 26-11-1980 y estaba formado por seis vocales de UCD (José María Álvarez del Manzano, Miguel Doménech, José Antonio Escudero, Antonio del Olmo, Carlos Plaza y José Ignacio Wert, en funciones de secretario), cuatro del PSOE (José María Calviño, Roberto Dorado, Francisco Fernández Marugán y Ramón González Redondo), uno del PCE (Antonio Kindelán) y otro de Coalición Democrática (Carmen Llorca). PSOE y UCD votaron a favor de Castedo, los otros dos partidos se abstuvieron. Sinova, 1983, p. 51.

${ }^{13}$ El País, 11-1-1981. En una línea parecida Diario 16, 10-1-1982. ABC, 10-1-1981 publicaba una breve entrevista titulada «Radiotelevisión española tiene arreglo».

14 Archivo Leopoldo Calvo-Sotelo (en adelante ALCS), Correspondencia, Caja Con-D, Cartas de F. Castedo, 16-8-1977 y 11-9-1980. 
que tenían conocimiento de los mismos en la Zarzuela, sin querer especificar más (...) A partir de este momento, la «izquierda» entró en verdadera euforia en la «casa» con la sorpresa y temor de los militantes o simpatizantes de UCD en el medio

Las consecuencias habían sido una visible mejora del tratamiento del PSOE en los informativos y que, por ejemplo, el día de su dimisión Suárez apareciera en pantalla luciendo camisa azul, «imágenes que estaban "expresamente fuera de uso". Nadie sabe la razón de su puesta en vigor». En resumen, «las decisiones que se están tomando en RTVE dañan gravemente la imagen del Gobierno, de UCD y, por supuesto, a los profesionales afectados», el ambiente en Prado del Rey es de «caza de brujas» y se extiende «la sensación de entreguismo y abandono» que «está produciendo desolación en personas que, sin ser militantes, han servido con lealtad, dedicación, sacrificio e ilusión» ${ }^{15}$.

El informe se acompañaba de dos notas, en una se denunciaba como el 15 de febrero de 1981 el Jefe de Informativos Iñaki Gabilondo «fue personalmente a preparar la información sobre el Congreso de Alianza Popular, e hizo una selección de textos y frases comentando expresamente que había que eliminar lo que pudiera tener carácter positivo». En la segunda se incluía una lista de once nombramientos de Castedo, acompañada de la adscripción ideológica de cada individuo (PSOE, PCE, UGT, CCOO). En algunos casos se habían añadido anotaciones más subjetivas: al lado de Gabilondo podía leerse: «PSOE (hermano con vínculos en Herry (sic) Batasuna)», y junto a Marino Peña, Director de la Segunda Cadena: «Amorfo. Manejable» ${ }^{16}$.

Así pues, Leopoldo Calvo-Sotelo sabía antes de su investidura que la situación en RTVE era potencialmente explosiva. Por supuesto, la percepción que se tenía desde la izquierda era distinta. El País alababa editorialmente «el coraje de Castedo», elogiaba los nombramientos de «profesionales de larga trayectoria en Televisión Española, expertos en organización, producción y programación (...) considerados como representantes del sector más liberal del actual organigrama, del que están mar-

15 ALCS, Investidura, 07, 116. Es probable que el informante fuera Miguel Doménech, cuñado de Calvo-Sotelo.

16 ALCS, Investidura, 07, 116, «Información del día 16 de febrero de 1981 sobre radio y televisión» y «Nombramientos de Fernando Castedo». Por ejemplo: «José Luis Balbín PSOE», «Eduardo Sotillos PSOE». 
ginados desde 1978» y se concedía amplio espacio a una entrevista en la que el nuevo director general exponía su programa ${ }^{17}$.

En este contexto la primera decisión de importancia que debía tomar el todavía candidato a presidente afectaba precisamente a la televisión: ¿Debía transmitirse en directo el debate de investidura? ¿Debía exponerse al riesgo de cometer un error irreparable ante las cámaras? ${ }^{18}$. La opinión de sus asesores fue terminante: «No debe admitirse la retransmisión completa que convierte un debate serio en un acto electoralista (...). Es básico que el realizador de T.V. sea un magnifico profesional y de absoluta confianza política. Si no es así peligra la imagen no solo del debate sino de Calvo-Sotelo para lo sucesivo» ${ }^{19}$. De este mismo criterio era su amigo Luis Ortiz, futuro Ministro de Obras Públicas: «El discurso-programa sirve al resultado de la votación en medida muy limitada. En consecuencia su destinatario no es tanto el hemiciclo como el público, bien directamente, bien a través de la prensa y radio. Debería poder introducirse alguna limitación en la retransmisión por TV, evitando la retransmisión íntegra en directo» ${ }^{20}$. Así se hizo, a pesar de la petición de la Junta de Portavoces del Congreso en carta a Fernando Castedo ${ }^{21}$. De este modo se pudo comunicar al presidente que: «En el Consejo del día 13 de febrero por vez primera los vocales de UCD y el Director General mantienen la misma postura en tema tan importante como la retransmisión, a través de diversos medios del acto de investidura ${ }^{22}$. Fue un espejismo.

A finales de marzo Diario 16 ya anunciaba que «sectores de UCD pretenden que Castedo deje RTVE» con el argumento de que «está llenando de rojos la casa» ${ }^{23}$. Tras un almuerzo con él, Fraga escribía en su diario que «mi paisano de Castroverde está dejando a la izquierda ha-

17 El País, 10, 14 y 17-1-1981.

18 Calvo-Sotelo Ibáñez-Martín, 2010, p. 463, «el nunca fue un hombre de la televisión (...) Le faltaban las cualidades telegénicas de Adolfo Suárez y de Felipe González de quienes decía que eran excelentes actores los dos».

19 ALCS, Investidura, 08, 142, «Desarrollo de la sesión». En una nota manuscrita Calvo-Sotelo apunta «Realizador Gustavo P Puig?» y debajo: «Fdo Castedo». Pelaz, 2016.

20 ALCS, Investidura, 03, 42, «Notas para el pleno de investidura», Luis Ortiz

21 ALCS, Investidura, 07, 121, Carta de Landelino Lavilla a Fernando Castedo. Carta de contestación del presidente del Consejo de TVE a Landelino Lavilla.

22 ALCS, Investidura, 07, 116. Se retransmitió en diferido a partir de las 22.30. Pelaz, 2016.

23 Diario 16, 27-3-1981. 
cer lo que quiera en Prado del Rey» ${ }^{24}$. Pronto se vio que el presidente del Gobierno no iba a poder quedarse al margen. El martes 14 de abril de 1981 Fernando Castedo era convocado a una reunión en Moncloa. Allí, según el relato que hiciera al periodista Justino Sinova, explicó al presidente cuales eran su planes para hacer una televisión que, para ser creíble, necesitaba dar también espacio a la oposición y no solo al Gobierno $^{25}$. La actitud de Calvo-Sotelo no fue muy receptiva. Después de un lustro controlando la pequeña pantalla, en UCD desconcertaba un director (que aunque afiliado al partido) no se plegaba a sus deseos, invocando una independencia que el Estatuto le garantizaba porque su mandato era de cuatro años y no podía ser cesado por el Gobierno. Según lo veía Castedo su objetivo era «convertir la radiotelevisión pública en un instrumento al servicio de la sociedad y aun del estado, pero no del Gobierno, y desde luego, no del partido en el poder. Hubo quien no lo entendió y también quien no quiso entenderlo. Entre unos y otros no nos permitieron conseguirlo» ${ }^{26}$.

\section{La «operación Salomé»}

La primera crisis estalló en mayo. El día 18 José Pedro Pérez Llorca en carta a Calvo-Sotelo le pedía que recibiera a los representantes de UCD en el Consejo de RTVE porque frecuentemente se encontraban sin criterio que seguir y sin respaldo a sus actuaciones ${ }^{27}$. El día 20 los medios denunciaron manipulaciones, presiones y censuras sobre el programa En este país en el que se había hablado de la OTAN ${ }^{28}$. Al día siguiente Castedo decidía el cese de Iñaki Gabilondo como jefe de In-

${ }^{24}$ Fraga, 1987, p. 240.

25 Sinova, 1983, p. 69 dice que Castedo fue convocado en marzo, pero en la Agenda personal del Presidente figura el 14 de abril, ALCS, Agenda, 1981. En una entrevista en 2012 Castedo aseguraba que Calvo-Sotelo le pidió la dimisión «a los tres días de ser presidente» https://www .youtube.com/watch?v=WBS3c6cM1hs. Esta versión también en Munsó, 2001, p. 169.

26 Castedo, 1983.

27 AGUN, JPPL, 263/033.

${ }^{28}$ Se afirmaba que el ministro de Defensa había presionado para que se suprimieran algunas opiniones desfavorables a la Alianza. El País, Diario 16, 20-5-1981. Pero también se denunciaba la «propaganda subliminal» con la que se asociaba la Alianza a la guerra nuclear, $A B C, 21-5-1981$. 
formativos por dos programas sobre el paro en Andalucía, críticos con el Gobierno y también por cierto, con la Junta andaluza. La tormenta política y mediática fue muy intensa y alcanzó de lleno al jefe del Ejecutivo. Diario 16 titulaba que «Calvo-Sotelo pidió su cabeza» y al mismo tiempo solicitaba la dimisión de Castedo por haberse plegado a esos deseos: «su pusilánime reacción (...) es la de un burócrata asustado que vende a quien haya que vender para salvar su propio pellejo (...) cada día que transcurra con Castedo al frente del ente público constituirá un insulto para todos los periodistas de este país» ${ }^{29}$. Desde el editorial de El País se defendía la gestión de Gabilondo y se intentaba justificar la postura de Castedo ante «el huracán de presiones y amenazas recibidas» que habrían hecho que «sus reservas de aguante moral y de resistencia física hayan quedado exhaustas». No obstante se advertía que era probable que «esa cabeza que ahora se ha hecho rodar no salve, a corto o medio plazo, la de sus propios verdugos $»^{30}$. El $A B C$, más comprensivo, señalaba que el cese era el «fruto de un cúmulo de errores y de abusos no cortados a tiempo» ${ }^{31}$. Años después el propio Calvo-Sotelo nos dejaría una opinión bastante elogiosa sobre Gabilondo, ya muy lejos de las presiones políticas ${ }^{32}$.

Curiosamente la percepción de los telespectadores no parecía ser la misma que la de los políticos de UCD. Varios informes del CIS en poder del presidente, revelaban que la mayor parte consideraba el Telediario de las 9 de la noche (el de más audiencia y presentado personalmente por Gabilondo) como bastante imparcial, y que solo entre un cinco y un seis por ciento pensaba que la información estaba «más bien inclinada a la izquierda» ${ }^{33}$. Da la impresión de que los dirigentes de UCD comenzaban a estar presos de una cierta paranoia. En una carta

29 Diario 16, 23-5-1981. También hubo un artículo de Pedro J Ramírez el 25-5-1981.

30 El País, 23-5-1981.

31 ABC, 23-5-1981.

32 «Guardo un excelente recuerdo de las entrevistas que me ha hecho a lo largo de muchos años (...) en suma, un excelente y extraordinario periodista», ALCS, Conferencias, 45, 07. (9-1998). El sustituto de Gabilondo fue Pedro Erquicia (1-7-1981), Montero, 2018, pp. 342-343.

33 Desde mayo el CIS incluía una pregunta sobre los «nuevos telediarios» que comenzaron a emitirse el 20 de abril. Hasta julio los que pensaban que la información era «imparcial» estaban entre el 49 y el $53 \%$. Entre un 23 y un $30 \%$ no sabían o no contestaban. ALCS, Opinión, 04, «Barómetro de la opinión pública, CIS, mayo 1981»; Opinión, 09, «Barómetro de la opinión pública, CIS, julio 1981». 
al presidente, Miguel Herrero le reprochaba haber entregado gratuitamente la Televisión y la radio «a quienes defienden un modelo de vida distinto a aquel que prometimos mantener y cuya tutela se nos encomendó» y le pedía que no hiciera lo mismo con la Universidad ${ }^{34}$. Con su actitud UCD se estaba poniendo en evidencia ante la opinión pública puesto que la audiencia no parecía percibir la supuesta manipulación izquierdista sobre la televisión, pero sí la que ejercían los centristas sobre su director.

Castedo fue requerido para comparecer ante la Comisión de Control de RTVE. Las intervenciones tanto de socialistas como de ucedistas, fueron en general comedidas. A los primeros no les interesaba poner en más apuros al todavía director general y los segundos tampoco querían seguir tirando piedras contra su propio tejado. Los más incisivos fueron los representantes del PCE y de Minoría Catalana. Castedo por su parte, «negó la existencia de presiones en el cese de Gabilondo y en el programa de la OTAN». Como señalaba El País, la comparecencia «concluyó con la placidez de una merienda entre amigos ${ }^{35}$.

En las semanas siguientes las polémicas sobre diversos programas y profesionales fueron una constante. Los centristas del Consejo parecían «decididos a cambiar su papel de consejeros de administración por el de censores», analizando con lupa los contenidos de cada programa. La estrategia parecía ser, en vez de cuestionar la orientación ideológica de la cadena, criticar la moralidad u oportunidad de sus emisiones ${ }^{36}$.

Las presiones sobre el presidente para que arreglase el «regalo envenenado» de Castedo arreciaron tanto en el partido como en el propio Consejo de Ministros ${ }^{37}$. Eso condujo a una segunda reunión en Moncloa el 1 de agosto, ahora ya «para arrancarle la dimisión». Calvo-Sotelo puso sobre la mesa una carta que Castedo había entregado a Suárez ofreciéndose a dimitir cuando se le solicitara. Según el relato de Sinova (que es el del propio Castedo) el director de RTVE adujo que se trataba de una mera «carta de cortesía», ante lo cual Calvo-Sotelo le anunció

34 ALCS, Correspondencia, Caja H-K, Carta de Miguel Herrero, 21-05-1981.

35 El País, 11 y 12-6-1981.

36 Entre otros ejemplos: Esta noche, presentado por Carmen Maura; un coloquio sobre sexo entre Susana Estrada y José Luis Martín Vigil en Mano a mano; la emisión del film Padre padrone, o la serie De carne y hueso por mostrar una presunta relación incestuosa, El País, 12-6-1981, 17 y19-7-1981.

37 Tiempo de política, 28-5-1981; El País y Diario 16, 17-7-1981. 
que «el partido está dispuesto a todo y ha decidido ya tu sustitución». Siguió luego un rocambolesco episodio en el que el presidente convocó a Castedo a una nueva reunión para el 19 de agosto a la que Calvo-Sotelo no acudiría ${ }^{38}$. En cualquier caso, desde ese momento la suerte del director general, aferrándose al cargo en contra del gobierno y del partido, estaba echada. La prensa hablaba abiertamente de su relevo y se mencionaban nombres concretos de posibles sustitutos ${ }^{39}$.

A comienzos de octubre la postura de Castedo se hizo ya insostenible. Un editorial de Diario 16 en primera página calificaba la situación de Televisión española como de «límite» denunciando la «incapacidad de gestión y falta de criterio del director general». La aparición en un debate televisivo del director de El Alcázar haciendo apología del golpismo, las presiones sobre el director del programa Parlamento, y la censura de un informativo sobre el PSOE en víspera de las elecciones gallegas, llevaban al periódico a pedir a los socialistas que retiraran su apoyo a Castedo. Citando al representante comunista en el Consejo se afirmaba que «los informativos están en el índice más bajo de credibilidad (...), la información es adormecedora (...) el soporte de la imagen ridículo» $\mathrm{y}$ «no se da una sola primicia informativa ${ }^{40}$. A esto se unieron unas explosivas declaraciones de Agustín Rodríguez Sahagún, presidente de UCD, señalando que el partido «no tolerará más (...) la instrumentalización socialista de la televisión pública (...) para atacar los valores de nuestro modelo de sociedad». Para El País, editorializando de nuevo, lo que estaba en juego era «el amaestramiento de Televisión con vistas a las próximas elecciones generales», mientras que Diario 16 expresaba su «enorme perplejidad» al contemplar como el periódico de Cebrián defendía a un director «que no cesa de lanzar a los pies de los caballos a quienes en Prado del Rey pretenden ejercer el periodismo con independencia». $A B C$, por su parte, denunciaba la aparición de listas de depurados, «profesionales que no coinciden con posturas de izquierda» ${ }^{41}$. A la mesa del presidente del Gobierno llegó incluso un in-

${ }^{38}$ Sinova, 1983, pp. 70-72 dice que ocurrió el 31 de julio, aunque según la agenda del presidente fue el 1 de agosto. No figura reunión con Castedo para el 19, ALCS, Agenda, 1981.

39 Cinco días, 11-8-1981; El País, 16-8-1981; 18-8-1981; 19-8-1981; 22-9-1981.

40 Diario 16, 8-10-1981. 1981.

41 El País, 9, 10, 11 y 13-10-1981; Diario 16, 9, 10, 11 y 17-10-1981; ABC, 9 y 10-10- 
forme de la asesoría jurídica sobre la posibilidad de que TVE (y la Cadena SER) hubieran violado la jornada de reflexión de las elecciones gallegas el día 19 por incluir unas declaraciones de Felipe González sobre el triunfo socialista en los comicios griegos ${ }^{42}$.

La llamada por El País «operación Salomé» se precipitó cuando Castedo anunció su intención de ofrecer una rueda de prensa «a tumba abierta y a muerte» para el 23 de octubre ${ }^{43}$. En UCD los ánimos estaban bajo mínimos después de conocerse los malos resultados de las elecciones gallegas del día 20 y pedían la cabeza del «Bautista». A las 9 de la noche del día 22 Castedo fue convocado a Moncloa. Los relatos de lo sucedido coinciden en lo esencial. Allí se encontró con el presidente del Gobierno, Pío Cabanillas, Rodríguez Sahagún, Adolfo Suárez e Ignacio Aguirre (portavoz del ejecutivo) y comprendió que su hora había llegado. Presentó su renuncia dejando claro que «se me exige la dimisión por haber hecho aquello para lo que se me nombró» ${ }^{44}$.

La incomodidad de Leopoldo Calvo-Sotelo ante el cese de Castedo parece obvia. Ante el fracaso de su primer intento en agosto, ahora se había pertrechado mucho mejor. Había obtenido el respaldo del partido y concretamente una carta de Rodríguez Sahagún en la que le pedía que pusiera «fin a la situación». La presencia de Pío Cabanillas (padrino político de Castedo) debía subrayar su soledad y la de Adolfo Suárez (quien propuso su nombramiento) aclararle el sentido de la famosa carta de «dimisión preventiva». No obstante la situación era tan violenta que, según el relato de Sinova, llegó a plantearse hasta una posible renuncia de Calvo-Sotelo. El comentario que añade el presidente en sus Memorias podría interpretarse como el reconocimiento de un cierto bochorno: «Esa es la triste suerte de todos los Directores de Televisión que en España han sido $»^{45}$.

42 ALCS, Partidos, 02, 14. (20-10-1981) El informe concluía que era difícil considerar esas declaraciones como atentatorias a las normas sobre propaganda electoral aunque se podía presentar una querella ante la Jurisdicción ordinaria contra los directores de los medios.

${ }^{43}$ El País, 21-10-1981. También estaba a punto una remodelación de los Servicios Informativos; Diario 16, 21-10-1981.

44 Sinova, 1983, pp. 75-77. Incluye la carta de dimisión. Castedo fue nombrado poco después Presidente del Banco Hipotecario, El País, 16-01-1982.

45 Calvo-Sotelo, 1990, pp. 66, 73 y 226-227 (notas 36 y 37). Incluye la carta de Rodríguez Sahagún. 
Es también interesante valorar la actitud de Adolfo Suárez ante esta crisis. En una cena con militantes de UCD el 7 de mayo de 1981 Suárez contó a sus compañeros de mesa que su candidato para RTVE siempre había sido José Ramón Caso, que en realidad no conocía a Castedo y que fue su desconfianza lo que le llevó a pedirle la famosa carta. Ya entonces (mayo) «consideraba que era imprescindible para UCD el cese de Castedo, muy proclive en su opinión al PSOE» como demostraba su política de personal. Su cese debía llevarse a cabo «cuando tuviese lugar el periodo de descanso parlamentario más inmediato para evitar una polémica mayor de la que se produciría en todo caso». En resumen, «Suárez estaba convencido de que con Castedo al mando de la Televisión UCD no ganaría nunca las elecciones» ${ }^{46}$.

En último término en la decisión de Calvo-Sotelo parece haber pesado de forma decisiva la opinión de uno de sus más cercanos colaboradores, José Pedro Pérez Llorca, Ministro de Asuntos Exteriores, muy preocupado por el tratamiento que se venía dando en televisión a la entrada de España en la OTAN. Aquí estaría también la explicación de la elección del sucesor de Castedo, el hasta entonces Secretario de Estado de Exteriores, Carlos Robles Piquer ${ }^{47}$. Otra versión, más improbable, concede mayor peso a las presiones de Manuel Fraga ${ }^{48}$.

El estruendo mediático y político fue ensordecedor, porque se ponía fin al intento de «neutralizar» TVE, pero también por el procedimiento de destitución y por el nombre del sucesor, hombre con cargos de responsabilidad en la Dictadura y por añadidura, cuñado de Fraga. El editorial de $E l$ País criticaba «la aberrante confusión entre partido, Gobierno y estado», mientras que el de Diario 16, reconociendo que deseaba la salida de Cas-

46 Archivo José Antonio Pérez González, «Transcripción del encuentro con Suárez», 7-5-1981. Cuando años después el autor de este texto se lo contó a Castedo (ambos entonces en el CDS), éste no se lo creyó «por considerar que Suárez había valorado siempre su gestión muy positivamente». Información obtenida gracias a la amabilidad de Darío Díez Miguel, autor de una Tesis doctoral sobre el CDS, Díez Miguel, 2017.

47 Pérez, 2017, pp. 488-489. Inocencio Arias recuerda un programa sobre la OTAN que «terminaba con una secuencia antológica: una orgía de misiles, llamaradas, hongos atómicos caían sobre diversas localidades mientras sonaba apocalípticamente el canto funerario Dies Irae», Arias, 2012, p. 117. El propio Robles consideraba determinante la intervención de Pérez Llorca. Robles Piquer, 2011, pp. 475-476

48 Eduardo Sotillos habla de una reunión de Fraga con Matías Rodríguez Inciarte para hablar de televisión, la víspera del nombramiento de Robles Piquer. Sotillos, 2002, pp. 159-160; Fraga, 1987, p. 265. 
tedo, se lamentaba de la oportunidad perdida por el Gobierno de nombrar ahora «a una persona independiente, con talante progresista y prestigio intelectual». Ya, ABC, Cinco días y Pueblo, se mostraban más comprensivos haciendo hincapié en las presuntas negligencias de Castedo.

Alfonso Guerra anunció una querella criminal contra el presidente por «un acto vergonzoso, irresponsable, delictivo, brutal, ilegal, vandálico y chapucero ${ }^{49}$. En la propia UCD, hubo tímidas voces discrepantes, como la de Fernández Ordóñez, que protestaron porque se pusiera a la Ejecutiva ante el hecho consumado y por lo poco apropiado del sistema elegido, esa nada sutil diferencia entre una «dimisión forzada» y una «dimisión sugerida» que fue como Calvo-Sotelo presentó el asunto. En el Consejo de administración se votó al sucesor por siete votos afirmativos y con la ausencia de la izquierda. En Prado del Rey un grupo de profesionales se solidarizó por medio de carta con el director cesante y alguno como Eduardo Sotillos terminó presentando también su dimisión como director de Radio Nacional, denunciando la existencia de «una campaña financiada para desacreditar a Castedo» ${ }^{50}$. En rueda de prensa, retransmitida en directo por la radio pública, el propio director saliente resumía sus razones para marcharse: «el deseo del Gobierno y de UCD» ${ }^{51}$. Un día después era más contundente en El País: «Mi dimisión supone la quiebra de la transición democrática en RTVE». No estuvo en la toma de posesión de su sucesor ${ }^{52}$.

\section{Robles Piquer: el director número trece}

La elección de Carlos Robles Piquer fue una decisión personal de Leopoldo Calvo-Sotelo, aunque no fuera su primera opción ${ }^{53}$. Buscaba un hombre con experiencia en la administración, sensible al tema de la OTAN y con un perfil conservador que le procurara un mayor apoyo de Alianza Popular en el consejo de administración de RTVE ${ }^{54}$. Según Ro-

49 Según el editorial de El País, 28-10-1981: «una necedad jurídica».

50 El País, 22-11-1981.

51 A partir de informaciones de El País, Diario 16, ABC, Pueblo, Ya, y Cinco días de 24-10-1981.

52 El País, 25-10-1981.

53 A Juan Luis Cebrián le contó que algunos ofrecimientos fueron rechazados y que le hubiera gustado nombrar a Gabriel Cañadas, embajador en Roma. También que Suárez estuvo de acuerdo. El País, 19-12-1982.

${ }^{54}$ Munsó, 2001,p. 177. 
bles, que ha dejado en sus Memorias un relato amargo y vívido de esta etapa, las palabras del presidente fueron: «te he pedido que aceptes este difícil encargo porque sé que tu no pactarás con los socialistas» ${ }^{55}$. No era miembro de UCD y tampoco quiso afiliarse ahora. Para curarse en salud, Calvo-Sotelo tomó la precaución de pedirle una carta de dimisión sin fecha, igual que hiciera Suárez con Castedo ${ }^{56}$.

Existía una buena relación personal entre Robles Piquer y el presidente, ambos habían coincidido ya en el primer Gobierno de la Monarquía y luego en diversos puestos en la administración. Aunque Robles no lo cuenta en sus memorias, la prensa publicó que el presidente le había ofrecido el cargo ya en julio y que habían hablado varios días antes del cese de Castedo $^{57} \mathrm{y}$, aunque explique que solo recibió una llamada de Calvo-Sotelo durante su etapa en RTVE, la agenda del presidente muestra que hubo varios encuentros entre ambos durante aquellos meses ${ }^{58}$. Curiosamente en las Memorias de Calvo-Sotelo no aparece ninguna referencia a la etapa de Robles Piquer en televisión, ni siquiera a su cese.

La impresión ante la opinión pública fue que tras el desastre gallego - y no antes como afirma Hunneus ${ }^{59}$ - en UCD había cundido el pánico, y que se estaba preparando el acuerdo con Fraga en la línea de la mayoría natural que aquel venía demandando. UCD no solo había renunciado al consenso con el PSOE sino que también lo había hecho respecto a sus propias señas de identidad centristas y moderadas. ¿Que otro sentido podía tener el nombramiento de lo que Guerra llamó un «mamut prehistórico salido del fascismo» ${ }^{60}$ ? . La idea de la «derechización» de UCD, que tanto daño haría a Calvo-Sotelo, comenzó a convertirse en un lugar común ${ }^{61}$. Un artículo de Sinova en Diario 16 sobre «el cuñadismo» recordaba la condición de Robles Piquer como «mamporrero» de Fraga en la Direc-

55 Robles Piquer, 2011, p. 482.

56 Robles Piquer, 2011, p. 483.

57 Diario 16, 25-10-1981.

58 Robles Piquer (2011): 478-479. En el telediario regional madrileño apareció Fraga en un mercado preguntando por el precio de los garbanzos. Calvo-Sotelo le pidió que la noticia no se repitiera en el telediario nacional. En la Agenda del presidente aparecen encuentros el 14-10 a las 20.00; el 31-10 a las 18.00; 13-1 a las 11; 11-2 a las 19.30; 29-5 a las 11.30. Y luego 22-7 a las 10 (cese) y todavía $27-7$ a las 18.45 y 21-9 a las 17.00 , ALCS, Agenda, 1981 y 1982.

59 Hunneus, 1985, pp. 373-374.

60 Powell, 2002, p. 370.

${ }^{61}$ El nuevo lunes, 26-10-1981; Cinco días, 27-10-1981. 
ción General de Información y apuntaba que lo que había hecho CalvoSotelo era «meter al enemigo en casa ${ }^{62}$. En este mismo diario el defenestrado Iñaki Gabilondo sostenía que «Solís ya puede volver a ser ministro. A partir de ahora entraremos disciplinadamente en el túnel del tiempo» ${ }^{63}$. A comienzos de diciembre en la Comisión de Control de RTVE en el Congreso hubo comparecencias del director saliente, del entrante y de los miembros del Consejo de administración. Castedo se atuvo a sus declaraciones y Robles Piquer, que explicó que Calvo-Sotelo le había dado «unas guías de actuación» para evitar «radicalismos», tuvo que defenderse además de las acusaciones de «caza de brujas» en su nueva política de nombramientos ${ }^{64}$.

Las dificultades de Robles Piquer, decimotercer director en la historia de RTVE, fueron enormes desde el primer día. Para empezar la izquierda no reconocía la legalidad de su nombramiento y los consejeros socialistas acudieron al Tribunal Supremo, que no admitió la petición a trámite ${ }^{65}$. Se elevó entonces recurso de amparo al Tribunal Constitucional que lo terminaría desestimando ${ }^{66}$. El Consejo de administración fue utilizado por el PSOE para promover una campaña de desgaste, azuzada desde El País, contra el Gobierno y su presidente. Las batallas en su seno, como recuerda Robles, fueron «extenuantes». En un intento por buscar un modus vivendi llegó a reunirse con Felipe González y con Jesús Polanco, pero el factor desequilibrante, a su juicio, fue la actitud de Alfonso Guerra, «muy irritado por el cese de su patrocinado y la disminución de la desproporcionada presencia de los suyos en la televisión única ${ }^{67}$. Ahora los papeles se habían invertido y era la izquierda la que atacaba al director general usando como argumento la política de personal, la programación o la censura ${ }^{68}$. Algunos de los argumentos esgrimi-

62 Diario 16, 26-10-1981. Robles anunció una querella, que luego no presentó.

63 Diario 16, 29-10-1981.

${ }^{64}$ El País, Ya, Diario 16, 4-12-1981. ) Joaquín Castro Beraza sustituyó a Erquicia al frente de la dirección de informativos (5-11-1981). Montero, 2018, p. 343.

${ }^{65}$ El País, 30-12-1981, 19-1-1982 y 18-11-1982.

${ }^{66}$ El País, 24-3-1982. El TC lo desestimó cuando ya Robles Piquer llevaba varios meses fuera del cargo.

${ }^{67}$ Robles Piquer, 2011, pp. 485 y 488. Guerra dice que cuando en el Consejo de RTVE le atacaban, Robles «se limitaba a introducirse un pañuelo en la boca para ahogar su ira por las invectivas que recibía», Guerra, 2007, p. 404.

68 Por ejemplo un Informe semanal sobre el estado de las cárceles, cortes en el telefilm Hijos y amantes, El País, 1-11-918; censura en el programa Historia del cine español, El 
dos resultaban, sin embargo, algo forzados, como cuando se cuestionó la decisión de no retransmitir en directo el debate sobre la OTAN en octubre de 1981, o el de la colza (que era lo mismo que hizo Castedo con el de investidura) ${ }^{69}$. Alfonso Guerra también denunció como «golpista» la información ofrecida sobre el juicio del $23 \mathrm{~F}^{70}$. Como recuerda Sotillos, «el PSOE protestaba porque LCS ocupara casi veinte veces más tiempo en pantalla que FG (sic), y el propio Robles Piquer, el doble que el principal líder de la oposición». También se denunciaron «corruptelas de las que se beneficiaban los periodistas situados al frente de los principales espacios». En suma, «TVE estaba, en 1982, en el centro del debate político y se analizaba, al milímetro, el contenido de sus informativos ${ }^{71}$.

A partir de marzo la ofensiva contra Robles Piquer fue general. Para empezar, el relevo de Castedo, que todavía seguía en cuestión, fue objeto de una interpelación en el Congreso por parte de Santiago Carrillo, contestada por el ministro de la presidencia Rodríguez Inciarte, ante la ausencia de Calvo-Sotelo. A última hora Carrillo solicitaba que se convocase otra sesión para reprobar a Robles Piquer. Poco después era el PSOE el que pedía el cese del director ante la Comisión de Control pensando que era más fácil conseguirlo en ese foro que no en el Pleno ${ }^{72}$. Prácticamente a la vez socialistas y comunistas exigían lo mismo en el Consejo de RTVE «por considerar su gestión irrespetuosa con el pluralismo político» ${ }^{73}$. El editorial de El País, presentaba la situación informativa de TVE como «el mejor y más claro exponente de cómo puede un Gobierno autodestruir su imagen (...) a base de mirarse

País, 12-12-1981. También se criticó la desaparición de la dirección de programas especiales, encabezada por José Luis Balbín, quien sin embargo seguía al frente de La clave, El País, 3-12-1981.

69 El País, Diario 16, 28-10-1981.

70 El País, 26-3-1982. Sobre la cual Robles se sentía bastante satisfecho. Robles Piquer, 2011, p. 488.

71 Sotillos, 2002, pp. 165, 171-172. Se abrieron expedientes a los directores de los programas Aplauso y 300 millones por posible publicidad encubierta, El País, 9-3-1982.

72 El País, 26-3-1982; 8-4-1982; ABC, 26-3-1982.

73 Un estudio comparado entre las noticias de portada de El País y de la primera edición del Telediario permitía concluir que «las prioridades informativas de TVE no coinciden (...) con los estados de opinión y los problemas realmente existentes en el país», $E l$ País, 27-3-1982. Diario 16, 8-5-1982 coincidía con este diagnóstico: «la realidad española está radicalmente ausente de TVE». 
al espejo y practicar el infantil deporte del autoelogio y el piropo hacia uno mismo» ${ }^{74}$

Mientras se sustanciaba la petición de cese, estallaba en Prado del Rey la «guerra de las cartas». Los profesionales de TVE se dividieron en dos bloques, uno en contra del director con 180 firmantes, otro a favor con 182 rúbricas $^{75}$. Se anunciaron sanciones contra los díscolos, que fueron luego anuladas. Pocas veces se había visto un enfrentamiento tan abierto en la casa. Según Robles Piquer, a quien sus detractores tildaban de «Roblespierre» por los pasillos ${ }^{76}$, «el control interno logrado (...) por los dos grandes partidos de la izquierda y por los sindicatos de su obediencia había llegado a ser abrumador y, a menudo, impenetrable» ${ }^{77}$.

En los primeros meses de 1982 Calvo-Sotelo, que había terminado asumiendo la dirección de UCD a finales del año anterior, constataba como su elección en RTVE le había creado un nuevo problema político, más grave si cabe, que el que heredó con Castedo. Así lo pudo comprobar precisamente en una entrevista en televisión con ocasión de su primer aniversario de gobierno. Ante las cámaras Rosa María Mateo le planteó que el cese de Castedo se había entendido «como un ensayo de la gran derecha y también como un cierto recelo del Gobierno hacia la libertad de expresión». Calvo-Sotelo respondió que «la derechización de UCD es una vieja cantinela que se ha repetido y no se ha probado nunca», que «se exageró mucho el alcance y el origen de aquella decisión» y que había «un cierto clamor popular» a favor del relevo en el Ente. La misma cuestión aparecería en otras entrevistas a partir de entonces $^{78}$.

La actitud de Fraga tampoco ayudaba. A su juicio, Robles estaba «haciendo un excelente y difícil trabajo en RTVE». Crecido tras el triunfo en Galicia no dudaba en plantear su proyecto de mayoría natural cada vez

74 El País, 31-3-1982. Por otra parte reconocía que durante el mandato de Robles se habían visto películas «que hubieran provocado hace seis meses desmayos e indignaciones a granel», y que se habían mantenido espacios polémicos como Esta noche, La clave o En este país, lo cual demostraba lo artificioso de la campaña de «la gran derecha» contra Castedo.

75 Robles Piquer, 2011, p. 485. 1982.

76 Sotillos, 2002, pp. 165 y 167. El País, 8, 9, 11, 12, 19, 20-5-1982; Diario 16, 8-5-

77 Robles Piquer, 1984.

78 ALCS, Conferencias, 35, 01, Transcripción entrevista 27-2-1982; Interviú, 6-101982 (Pedro Altares y Rosa M. ${ }^{a}$ Mateo); El País, 19-12-1982 (Juan Luis Cebrián). 
que podía y el control de la televisión era una pieza clave ${ }^{79}$. En una nota al presidente, Fraga le explicaba que no era suficiente con estar presente en el Consejo de administración, si se estaba ausente en los «órganos técnicos o instrumentales» ya que el director de un programa «puede tener una exquisita neutralidad pero ser saboteado por un oscuro redactor que dé un sesgo parcial a una noticia». Era preciso que cada partido tuviera «un cupo de personal fijo en RTVE, que aparte de su cualificación profesional tenga una adscripción política». Por eso, de cara a la retransmisión del Mundial de 1982, pedía para su partido 50 contratos sobre un total de 550, «una petición muy razonable, habida cuenta de la abrumadora mayoría de personal de reconocida adscripción política izquierdistas en RTVE» ${ }^{80}$

\section{Nasarre y la paz democristiana}

La crisis del centrismo culminó en el desastre electoral de Andalucía en mayo de 1982, a pesar de la selección de «buenos profesionales del Medio afines al objetivo que se persigue», tal como rezaba una nota de Jaime Lamo de Espinosa al presidente sobre el nombramiento de candidatos para el centro regional andaluz ${ }^{81}$, y de los esfuerzos confesados de Robles Piquer «para que la catástrofe previsible de UCD quedara paliada por imágenes en las que se disimulara, tanto como fuera técnicamente posible la triste verdad de unos mítines desdeñados por el pueblo» ${ }^{82}$. Tras la debacle, muchos en UCD miraron de nuevo a Televisión española y al Gobierno preguntándose qué estaba pasando. Según El País el líder mejor tratado en la pequeña pantalla durante la campaña había sido Manuel Fraga $^{83}$. En un informe remitido al presidente se afirmaba: «Media España no entendió lo de Castedo y la otra media no entiende lo de Robles Piquer. (...) ¿No hay personas de UCD de verdad y normales, capaces de

79 Tras una entrevista el 1-11-1981 para «mejorar los modos y maneras, con especial referencia a los medios públicos de comunicación», Fraga constataba la actitud esquiva de Calvo Sotelo: «no quería enterarse». Fraga, 1987, pp. 267 y 282. Se entrevista con Robles el 4-7-1982 (p. 289).

${ }^{80}$ ALCS, Partidos políticos, 02, 20, «Temas Alianza Popular. Personal contratado por RTVE para los Mundiales» (sin fecha).

81 ALCS, UCD, 06, 192, «Candidatos para TVE en Andalucía». Se daban tres nombres para Director del Centro Regional y uno para el de los Servicios Informativos.

${ }_{82}$ Robles Piquer, 2011, p. 491.

${ }^{83}$ El País, 31-5-1982. 
dirigir el Ente autónomo RTVE, dando así una buena imagen del Partido en el medio que da más imagen» ${ }^{84}$.

El debate parlamentario pedido por Carrillo meses atrás fue finalmente convocado para el 15 de junio, a pesar de los intentos de UCD para retrasarlo ${ }^{85}$. Con el grupo centrista menguado por las deserciones y minado por las divisiones (los seguidores de Fernández Ordóñez y los de Suárez le acusaban de favorecer a Fraga) la suerte de Robles Piquer parecía echada ${ }^{86}$. Aunque la votación no era vinculante, una censura parlamentaria podría provocar una crisis política de imprevisible alcance ${ }^{87}$. Según Guerra, Felipe González le llamó entonces para pedirle que retirara el asunto del orden del día porque «había recibido él una llamada del presidente del Gobierno, insinuando que podía abandonar su responsabilidad». A pesar de sus reticencias, tras comprobar «que el peligro de vacío de poder era real, opté por recomendar a algunos diputados que no acudiesen a votar» ${ }^{88}$. Por lo que publicó la prensa, Calvo-Sotelo había amenazado con disolver las Cortes. El pacto (negado entonces por Guerra) incluía el compromiso de cesar a Robles Piquer después de los Mundiales y apoyar la candidatura de Joaquín Ruiz Giménez para Defensor del pueblo (más tarde frustrada $)^{89}$.

Tras este episodio, el director de RTVE estaba «virtualmente destituido», aunque no todos le daban por perdido ${ }^{90}$. En un informe al presidente, el ministro José Luis Álvarez (que acabaría en AP) le pedía que no aceptara que le impusieran la sustitución porque «se interpretaría como una gran debilidad y como que no defiendes a las personas que tú nombras». El efecto sería «malísimo», desmoralizaría a los altos cargos de la administración y a los periodistas de medios afines «porque pensarían que no se está seguro sirviendo a UCD, sino que es mejor ponerse enfrente porque son los que ganan» ${ }^{91}$. La gota que colmó el vaso fue la división en el Consejo de administración entre los propios centristas.

${ }^{84}$ ALCS, UCD, 10, 221, «Informe crítico tras el 23-M (Expuesto por M Fombuena, en el Comité Ejecutivo Regional de UCD-Andalucía, celebrado el 31.5.82)».

85 El País, 31-3-1982.

86 ALCS, UCD, 06, 192, Carta de Jaime Lamo, 15-06-1982.

87 El País, 7, 10 y 13-6-1982.

${ }^{88}$ Guerra, 2007, p. 405. 23 diputados del PSOE y 7 del PCE se ausentaron del hemiciclo. Entre ellos Felipe González, escayolado a consecuencia de un accidente.

${ }^{89}$ El País, Diario 16, 16-6-1981.

90 El País, Diario 16, Ya, 17-6-1982.

91 ALCS, UCD, 05, 173, «Informe de JLA», 14-6-1982. 
Los suaristas José Antonio Escudero y Antonio del Olmo se sumaron «a los ataques de la izquierda, probablemente instruidos por el ex ministro Rodríguez Sahagún (...). Unidos a los socialistas y al comunista formaron una mayoría ocasional en el Consejo» acusándole todos a una de fraguista $^{92}$. La emisión poco después del programa «Golpe a la turca», en el que se quiso ver una cierta apología del golpismo, fue el mazazo final, y la excusa para que Sahagún enviara una nueva carta a Moncloa, reeditando su papel en el cese de Castedo ${ }^{93}$. La Comisión de control parlamentario, por su parte, pedía al Consejo de RTVE que abriera a su director «un expediente investigador para dirimir sus responsabilidades», lo cual se hizo por unanimidad, como también fue unánime la resolución en la que se establecía su «negligencia objetiva». La situación, según Robles, era «grotesca» porque el programa podía ser inoportuno pero lo que se le reprochaba era no haber ejercido la censura previa sobre su contenido ${ }^{94}$.

El desprestigio del director de RTVE era ya el de Calvo Sotelo. Según El País su nombramiento había sido «una de las decisiones que más le han erosionado desde su llegada al poder ${ }^{95}$. El gobierno estaba dividido y el partido también. A principios de julio Calvo-Sotelo abandonaba la presidencia de UCD en manos de Landelino Lavilla, quién de inmediato requirió la cabeza de Robles Piquer por el mismo procedimiento de la «dimisión-destitución» (carta mediante) que se usara con Castedo y con un único argumento, según Robles: «mi condición de cuñado de Fraga» ${ }^{96}$. La decisión del presidente le causó una no disimulada decepción, primero, porque si hemos de creer a $A B C$, no sabía lo que le esperaba cuando aquella mañana fue llamado a Moncloa; segundo, porque como dice en sus memorias, su parentesco era perfectamente conocido cuando se le hizo «el difícil encarguito» y tercero porque, según le reprocharía por carta posteriormente, «el único motivo que me diste a mí para el relevo en RTVE» fue «el riesgo de que mi nombre provocara un áspero debate al reabrirse el Parlamento en septiembre» cuando resulta que luego el presidente con-

92 Robles Piquer, 2011,pp. 486-487.

93 Robles Piquer, 2011, p. 487; Sotillos, 2002, pp. 160-161. Tras la polémica suscitada, el programa en cuestión volvió a emitirse días después para Canarias. El País, 20-61982.

94 El País, 1, 3, 8, 9, 15-7-1982; El nuevo lunes, 5-7-1982.

95 El País, 10-6-9182.

96 Robles Piquer, 2011, p. 491. 
fesó que la decisión de disolver la había tomado con anterioridad ${ }^{97}$. Años después todavía se seguía preguntando «si no habría sido lógico aguantar unos pocos meses más la incómoda presión guerrista, que esperó recuperar con mi relevo alguna parte del terreno perdido en RTVE, en vísperas de las elecciones del $82 \gg^{98}$. Para la prensa, era el resultado lógico de un situación agónica que ya no podía mantenerse más y la prueba de que Lavilla quería ejercer sus poderes ${ }^{99}$. Según Fraga en la dimisión había pesado tanto como «la presión de la izquierda, (...) el temor de que nos ayudara» ${ }^{100}$.

El nuevo director, nombrado el 23 de julio de 1982, fue Eugenio Nasarre, ex director general de asuntos eclesiásticos, democristiano, hombre de confianza de Iñigo Cavero y el primer periodista en ocupar el puesto ${ }^{101}$. Su misión era conseguir la paz en Prado del Rey de cara a la celebración de unas elecciones generales, que fueron convocadas un mes después, y en las que las perspectivas de UCD ya eran desastrosas, hiciera lo que hiciera Nasarre. En palabras de Sotillos cumplió su mandato «con dignidad». Según Julio Feo este nombramiento contribuyó a ponerles «las cosas menos difíciles» ${ }^{102}$. Justino Sinova señala que tuvo que hacer frente a cuatro problemas: el acoso de los suaristas, la oposición a su proyecto de información religiosa y a la cobertura del viaje del Papa, la oposición de la derecha en Prado del Rey y «la acción subversiva y dislocante de José Luís Balbín» ${ }^{103}$. En Radio Nacional el director y otros altos cargos dimitieron por discrepancias «en torno a los criterios informativos» ${ }^{104}$.

Visto desde la perspectiva de Robles Piquer (que antes de las elecciones entró a militar en AP), el trabajo de Nasarre consistió en liquidar lo que él había conseguido. Como le señalaba a Calvo-Sotelo: «Se

97 AGUN/JPPL/263/052/4.5 Carta de 24-9-1982.

98 Robles Piquer, 2011, p. 493. Robles fue nombrado Director del Instituto de Cooperación Iberoamericano, el mismo cargo que ocupaba Castedo antes de pasar por RTVE.

99 El País, Cinco Días, El Alcázar, ABC, Informaciones, Diario 16, 23-7-1982.

${ }^{100}$ Fraga, 1987, p. 290.

101 Según su testimonio, su cercanía a Cavero y no a Lavilla (como publicó la prensa) fue el factor decisivo en su nombramiento. Entrevista Eugenio Nasarre, 12-9-2018

102 Sotillos, 2002, p. 159; Feo, 1993, p. 134. El nuevo director de informativos (el cuarto de la etapa Calvo-Sotelo) fue Juan Roldán, Montero, 2018, p 344.

${ }_{103}$ Sinova, 1983, p. 98. El propio Nasarre coincide con esta apreciación (entrevista 129-2018).

${ }^{104}$ El País, 8 y 9-10-1982; Diario 16, 9-10-1982. 
ha producido ya, pese a avisos oportunos, un inteligente entreguismo sólo apenas maquillado, de tal manera que los socialistas y sus aliados - a los que soporté, porque así me lo pediste, durante nueve meses incluso con quebranto de mi salud - no necesitarán cambiar nada si realmente llegan al poder» ${ }^{105}$. En plena campaña electoral una nueva nota al Presidente del Gobierno certifica esta sensación. El informante anónimo le hacía saber, «aunque supongo no servirá de nada», que los responsables de los Telediarios habían «telefoneado a corresponsales de TVE para decirles que en ninguna crónica hagan críticas ni alusiones negativas sobre los partidos Socialistas», que el director de los Servicios informativos iba diciendo que la mejor entrevista de las grabadas a los líderes políticos había sido la de Suárez y la más floja la de Lavilla. Y para terminar, como un extraño guiño al cese de Castedo, que «esta semana se han programado en TVE dos programas sobre el paro decisivos. Deben pararse» ${ }^{106}$. Según El País, la corrupción no desapareció, la programación seguía siendo aburrida, aumentaron los programas religiosos y la «ley del embudo» continuaba aplicándose para los partidos de la oposición ${ }^{107}$. Hubo gran expectación ante la posibilidad de un debate televisado entre los candidatos, pero finalmente no se celebró. Según el estudio de El País el reparto de tiempos en pantalla fue mas proporcionado que en otras ocasiones ${ }^{108}$. Los resultados de las elecciones de 1982 fueron concluyentes, con televisión o sin ella, UCD había pasado a la historia.

Al finalizar su mandato presidencial Calvo-Sotelo recibió dos cartas de despedida, una de Robles Piquer y otra de Eugenio Nasarre en la que ambos le agradecían la confianza depositada, a la que procuraron corresponder en unos tiempos nada fáciles ${ }^{109}$. Castedo no le envío ninguna.

105 AGUN/JPPL/263/052/4. 5, Carta de Robles Piquer, 24-09-1982.

106 ALCS, UCD, 07, 208.

107 El País, 12-9-1982 y 15-10-1982.

108 El País, 18 y 27-10-1982. Nasarre sigue considerando que el tratamiento informativo de aquella campaña fue lo mas sobresaliente de su breve mandato junto con la cobertura del viaje papal (entrevista 12-9-2018). La cobertura de la noche electoral fue especialmente cuidada, Montero, 2018, p. 344.

109 ALCS, Correspondencia, Caja P-R, Carta de Carlos Robles Piquer, 2-12-1982; Caja M-OR, Carta de Eugenio Nasarre, 10-01-1983. 


\section{La fallida aventura de la televisión privada}

La relación del gobierno de Calvo-Sotelo con RTVE corrió pareja con su intento frustrado de legalizar la televisión privada en España. En el programa de UCD, aprobado en su II Congreso, se decía que la defensa de la libertad de expresión «conlleva la necesidad de que el estado renuncie al monopolio que actualmente ostenta en el ámbito de la televisión» y se relacionaba este hecho con el avance que había supuesto la elaboración del Estatuto de RTVE «para lograr una televisión estatal saneada financieramente y con un nivel máximo de profesionalidad en cuanto a sus contenidos» ${ }^{110}$. A nadie se le escapaba que no sería tan gravoso que la televisión pública quedara neutralizada políticamente, si se abría la puerta a que empresas de comunicación (supuestamente siempre más afines al centro derecha que a la izquierda) pudieran hacer la competencia al Ente. Aunque en su discurso de investidura Calvo-Sotelo no hizo referencia a esta cuestión, si consta que Matías Rodríguez Inciarte le hizo llegar la sugerencia de incluirlo ${ }^{111}$. En otro documento remitido al presidente tras el 23-F con propuestas para la regeneración de la vida democrática, se apuntaba que «El problema de la privatización de la TV está ahí. El Estado no puede seguir manteniendo el monopolio exclusivo de este medio. Este problema tiene que resolverse, conforme a los criterios de los países libres y cuanto antes»112.

La tensión con Castedo convirtió el asunto en tan urgente que el partido presionó al presidente ${ }^{113}$. En mayo de 1981, 50 diputados de UCD presentaban por su cuenta en el Congreso una proposición de ley para regular la televisión privada ${ }^{114}$. En julio, en el manifiesto de la llamada «Plataforma moderada», liderada por Miguel Herrero, se instaba a la regeneración del centrismo entre otras cosas «mediante la regulación de la libre iniciativa en RTV (sic) y la efectiva objetividad de las emisoras

110 II Congreso Nacional de UCD. Ponencias, Palma de Mallorca, 6, 7, 8 febrero 1981, p. 111.

111 ALCS, Investidura, 03, 41, «Programa de investidura: medidas que se podrían incluir», MRI. «19. El gobierno autorizará el establecimiento de emisoras privadas de televisión y continuará el proceso ya iniciado de privatización de medios de comunicación».

112 ALCS, UCD , 06, 201, «Notas sobre una nueva ética para la vida democrática».

113 Calvo-Sotelo, 1990, p. 66. Nasarre lo vincula también al problema con Castedo. Nasarre, 1984.

114 El País, 28-5-1981; Diario 16, 30-5-1981; ABC, 27 y 28-5-1981. Entre los firmantes: José Luis Ruiz Navarro o Modesto Fraile. 
de titularidad pública» ${ }^{115}$. Finalmente Pío Cabanillas, entonces ministro de Presidencia, llevó la cuestión a Consejo de Ministros el 31 de julio de 1981. La idea era hacer la regulación por decreto «mediante un modelo intervencionista de gestión indirecta en régimen de concesión» ${ }^{116}$ y para ello contaba con un informe favorable del Consejo de Estado. La propuesta chocó con la oposición de Fernández Ordóñez, que filtró a los medios su postura favorable a hacerlo mediante Ley Orgánica pactada con el PSOE. En la rueda de prensa posterior al Consejo el presidente se vio obligado a responder que en el gobierno había habido debate pero que existía «unanimidad en lo esencial», es decir, «que UCD se ha manifestado en principio a favor de la autorización de las televisiones privadas» ${ }^{117}$.

Las espadas quedaron en alto hasta el Comité Ejecutivo de UCD celebrado el 20 de agosto de 1981 (precisamente el día en el que supuestamente Castedo debería haber sido cesado). Ordóñez y Adolfo Suárez encabezaron la oposición a la regulación por decreto y el proceso quedó congelado. Sinova apunta que Suárez «a lo que se oponía de verdad era a que dieran la televisión privada a los amigos de Calvo-Sotelo» ${ }^{118}$. Para la izquierda, tal y como reflejaba un editorial de El País, el temor era que «El Gobierno compense la relativa merma de influencia en Prado del Rey con el control directo o indirecto de los canales privados del futuro», es decir, cambiar el «monopolio estatal» por el «oligopolio gubernamental»119.

El segundo intento se produjo tras la salida de Fernández Ordoñez del Gobierno en agosto. Pío Cabanillas pasaba a Justicia y entraba en Presidencia, precisamente Matías Rodríguez Inciarte, a quien le preocupaba que la televisión pública pudiera llegar a las manos del Partido Socialista tras unas elecciones que daba por perdidas ${ }^{120}$. El 23 de octubre en una «sesión realmente dramática» tras el descalabro gallego y el cese de Castedo, la vía del decreto volvía a encontrar oposición en la Ejecutiva de UCD. Según recuerda Inciarte, la polémica «fue en algunos mo-

115 Herrero, 1993, pp. 242 y 246-248.

116 Quintana, 2007, p. 124.

117 ALCS, Consejo de Ministros, Transcripción rueda de prensa del presidente, 31-71981.

118 Sinova, 1983, pp. 181-183.

119 El País, 3-9-1981.

120 Sinova, 1983, p. 184. 
mentos tan áspera y con posiciones tan alejadas que me parecía estar asistiendo a la confrontación entre dos partidos políticos distintos (...) la escisión socialdemócrata primero y la suarista después ratificaban al poco tiempo lo acertado de esta impresión» ${ }^{121}$. Cerró la discusión el presidente del Gobierno «diciendo que se comprometía a un debate monográfico sobre la televisión privada y sobre la aplicación del estatuto de TV y sus relaciones con la gestión de la misma: La TV no será un servicio de UCD pero tendrá que respetarse el estatuto» ${ }^{122}$, una prueba más de la relación que se establecía entre las dos cuestiones y de los difíciles equilibrios que debía hacer Calvo-Sotelo ante quienes querían imponer la voluntad del partido sobre la del gobierno. El debate se reprodujo en la Ejecutiva Nacional del 2 de noviembre, lo que llevó a Emilio Attard a señalar que el verdadero problema era que el partido estaba ejerciendo una «especie de contragobierno que ha dado lugar a que por tercera vez tengamos que hablar en esta sesión del problema de la televisión privada sin haber alcanzado solución» ${ }^{123}$. Precisamente para El País las disensiones sobre la televisión fueron fue «el punto clave de la ruptura» entre Calvo-Sotelo y Rodríguez Sahagún que condujo a que aquel asumiera el liderazgo del partido ${ }^{124}$.

Mientras tanto, la sociedad Antena 3 (promovida por La Vanguardia, $A B C$, Grupo $\mathrm{Z}$ y Europa Press) había presentado un recurso al Tribunal constitucional reclamando el derecho a gestionar la televisión privada. Esto obligaba a esperar, aunque el Grupo parlamentario centrista ya contemplaba incluir esta ley para su tramitación ${ }^{125}$. Las otras empresas de comunicación con pretensiones, Radiotelevisión 16 (del Grupo 16 que había fichado como director a Iñaki Gabilondo), Tele 80 (patrocinado por la Editorial católica), PRESA (del grupo PRISA) y Tele-Ser (de la cadena SER), estaban también a la expectativa. El 31 de marzo de 1982, el alto tribunal dejaba al gobierno la capacidad para decidir cuando implantaba la televisión privada, pero sentenciaba que debía hacerse mediante Ley orgánica. Rápidamente el Consejo de Ministros

121 Rodríguez Inciarte, 1984, p. 721.

122 Attard, 1983, p. 268.

123 Atttard, 1983, p. 271.

124 El País, 11-11-1981.

125 ALCS, UCD, 06, 192, Programa legislativo mínimo (enviado por Jaime Lamo de Espinosa). También se hacía referencia a la «concesión del tercer canal a las Comunidades Autónomas». 
aprobaba un proyecto de Ley de estas características «sobre el ejercicio de la libertad de expresión en las emisoras públicas de radiodifusión y televisión» y otro que regulaba «la gestión indirecta del servicio público de Radiodifusión y televisión». Las concesiones se harían por seis años prorrogables, previo concurso público y se atendería entre otros a criterios como «la relación en la programación entre la producción nacional y extranjera (...) el tiempo de programación educativa o cultural y la viabilidad profesional y económica del proyecto ${ }^{126}$. La prensa recibió la noticia de forma positiva. Aunque había dudas sobre el procedimiento elegido y sobre las posibilidades reales de implementación, Pedro J. Ramírez afirmaba enfáticamente que Rodríguez Inciarte era «el hombre que más ha hecho por mejorar los niveles de felicidad cotidiana de los ciudadanos» ${ }^{127}$. El fin de la legislatura hizo ya imposible su aprobación en las Cortes. El PSOE nunca había querido la televisión privada pero en este caso, la culpa no fue de la oposición: «el sabotaje fue dirigido principalmente desde el interior» ${ }^{128}$.

En unas líneas preparadas para una intervención posterior a su renuncia como presidente de UCD en julio de 1982 Calvo-Sotelo hacía balance de su actuación con respecto a la pequeña pantalla. Reconocía que la televisión se había convertido «en un problema cotidiano, en un factor de tensión innecesaria de convivencia y veía «en todo este asunto el trasfondo que se deriva de las ansias de control partidario de un medio, al que por su situación de monopolio se atribuyen poderes mágicos de influencia». La solución sería «la concurrencia de una oferta televisiva plural (que) aliviará decisivamente de tanta tensión a un medio como este» ${ }^{129}$. Con su característica sorna galaica el presidente comenta en sus Memorias que Rodríguez Inciarte «se empeñó en la Televisión privada: algún día me ayudará a contar por qué se quedó el proyecto sobre la mesa» ${ }^{130}$.

126 ALCS, Consejo de Ministros, Orden del día 2-4-1982; Orden del día y Referencia de lo tratado en el Consejo, 16-4-1982. Quintana, 2007, p. 125.

127 Diario 16, 17 y 18-04-1982; El País, 18-04-1982; ABC, 13 y 18-04-1982.

128 Rodríguez Inciarte, 1984, p. 720.

129 ALCS, UCD, 10, 220, «Posibles temas de coloquio y líneas argumentales sobre ellos» (7-1982).

130 Calvo-Sotelo, 1990, p. 175. Rodríguez Inciarte sigue atribuyendo a la difícil situación interna de UCD el fracaso de su iniciativa (entrevista 29-5-2018). 


\section{Conclusiones: encerrados con un solo juguete}

En una ocasión le preguntaron a Leopoldo Calvo-Sotelo si sabía quien era JR, el protagonista de la serie Dallas, a lo que contestó con sorna que no veía el programa pero que sabía que era el malo de la película ${ }^{131}$. La anécdota ilustra el poco interés que el presidente tenía por un medio que «engrandece lo banal y trivializa lo trascendente» ${ }^{132}$. Sin embargo, como muchos otros, también había visto las consecuencias de su manejo por Adolfo Suárez en 1977 y 1979 y es que, como apunta Eugenio Nasarre: «Todos estaban fascinados por el uso de tan diabólico invento» ${ }^{133}$. Según Manuel Palacio: «El principal lastre para los políticos españoles de la transición (fue) (...) la perversa lógica de sus creencias sobre el poder omnímodo y los posibles efectos de la televisión». Esto explica que

TVE se convertirá en los años 1980 y 1981 (y por extensión hasta la victoria electoral del Partido Socialista en octubre de 1982) en uno de los elementos medulares del conflicto político entre partidos. En particular, para el Partido Socialista será central en sus estrategias de desgaste del gobierno ucedista y en sus propuestas de regeneración de la vida pública ${ }^{134}$

Calvo-Sotelo heredó una situación nueva en el terreno de la televisión. El acuerdo entre UCD y PSOE, que alumbró el Estatuto y el nombramiento de su primer director, imponía unas reglas que resultaron ser de muy difícil cumplimiento. Ni el sistema ni el hombre elegido para implementarlo probablemente fueron los más adecuados. El sistema politizaba el Consejo de administración al que convertía en una réplica del Congreso; y el hombre, aunque militante de UCD, se tomó tan en serio su independencia, que pronto despertó las suspicacias de los suyos, que deseaban hacer valer su precaria mayoría para controlar la televisión en un momento en que el centrismo iniciaba su imparable declive. Calvo-Sotelo no podía cambiar el sistema, así que optó por sustituir al hombre. Carlos Robles Piquer fue el elegido para enderezar la situación, pero enseguida se vio que conseguía el efecto contrario. La izquierda, que tanto había defendido a Castedo, pasaba ahora a denostar a su sucesor, a quien incluso

\footnotetext{
131 López de Celis, 2013, pp. 84-95.

132 Calvo-Sotelo, 1990, pp. 51-52.

133 Nasarre, 1984.

134 Palacio, 2012, pp. 207, 208 y 230.
} 
negaba la legalidad de su designación. A esta tarea se iba a sumar un sector de la propia UCD, que interpretaba que el nuevo director venía de la mano de la gran derecha o la «mayoría natural» de la que hablaba su cuñado Fraga. Si la derrota de Galicia supuso la defenestración de Castedo, la de Andalucía, selló la suerte de Robles Piquer.

El papel que le tocó a Calvo-Sotelo en este asunto fue bastante desairado. El partido, primero le exigió el cese de Castedo, al que no había nombrado, pero más tarde también el de Robles, del que sí era responsable, usando en ambos casos un bochornoso subterfugio. Por su parte, la izquierda primero defendió a Castedo y terminó luego salvando al presidente de una sonora derrota parlamentaria a causa de Robles Piquer. La televisión se convirtió, de forma seguramente inesperada para el presidente, en uno de los caballos de batalla que indudablemente más le desgastaron durante su breve mandato, mientras él intentaba alcanzar otros objetivos políticos como la entrada en la OTAN, la aprobación de la LOAPA, o el ANE y hacía frente a la crisis de la colza, o a la amenaza golpista y terrorista. Como dejó escrito El País, tomando en préstamo de Juan Marsé el título de una de sus novelas, buena parte de los políticos españoles parecían «estar encerrados con un solo juguete, por su obsesión casi monomaníaca con los asuntos televisivos. Se diría que, para ellos, la pantalla mágica, o la caja tonta, es una fuente inagotable y casi única de satisfacciones y de disgustos» ${ }^{135}$.

En el seno de UCD, la cuestión de la televisión vino a complicar más los delicados equilibrios de poder internos. Las distintas familias se enfrentaron públicamente, utilizando como arma arrojadiza la política de nombramientos, los contenidos de los programas, (que podían ser según las circunstancias, demasiado progresistas o en exceso conservadores) y los minutados del telediario. La labor del director en el Consejo de administración se hizo casi imposible, cuando además las sesiones eran luego glosadas por la prensa afín y la hostil. En medio, Leopoldo Calvo-Sotelo, que en principio intentó mantenerse al margen de los asuntos del partido (no en vano no había asumido su presidencia) y centrarse en las tareas gubernamentales, pero que pronto se vio arrastrado a la batalla, asumiendo tras el fracaso gallego el liderazgo de UCD y la decisión personal de nombrar a Robles Piquer, quizá más preocupado por la forma en que TVE trataba la entrada en la OTAN que por otra cosa.

135 El País, 1-7-1982. 
En realidad, como se vio, UCD no tenía un verdadero proyecto para RTVE, más allá de su instrumentalización. Por eso, ante su incapacidad por controlar Prado del Rey, empezó a desarrollarse otra batalla por la legalización de la televisión privada. Este asunto se convirtió en un problema de primera magnitud porque el gobierno pensó que al liquidar el monopolio se podía reducir la presión sobre el Ente. Y también porque Rodríguez Inciarte comenzó a ver como inevitable el triunfo del PSOE y con él una larga etapa de gobierno socialista, frente a la cual la existencia de una televisión privada podía ejercer de eficaz contrapeso. Pero de nuevo, las divisiones internas en UCD fueron decisivas y singularmente la actitud de Suárez y Fernández Ordóñez, que utilizaron este tema para escenificar sus disensiones, echar un pulso a Calvo-Sotelo al que acusaban de «derechización», y justificar al final su salida del partido.

La cuestión de la televisión privada determinó también en buena medida la actitud de la prensa ante RTVE y por extensión ante UCD y su Gobierno. Como apunta Quintana, las empresas periodísticas «encararon el problema de la televisión pública como un obstáculo a sus intereses en la industria audiovisual», de tal manera que «la intensidad en la crítica hacia RTVE dependió en gran medida del tratamiento favorable o desfavorable del Gobierno hacia los grupos de comunicación». Cabe concluir con esta autora que la prensa sobreactuó en su crítica al Ente subrayando, por ejemplo, su pésima gestión económica o también su excesiva instrumentalización política ${ }^{136}$.

Por supuesto el control sobre RTVE no desapareció tras la derrota de UCD, pero la mayoría absoluta del PSOE haría su manejo mucho más sencillo y pasarían todavía unos años hasta que se legalizara la televisión privada. En el debate sobre el estado de la nación de 1985 Leopoldo Calvo-Sotelo tendría ocasión de devolver a sus adversarios algunas de las críticas de las que fue objeto:

La Televisión pública se ha convertido en un lugar de opinión mucho más que de información, y de opinión sesgada, ni siquiera de opinión partidista. Yo tengo la convicción de que al servicio de no sé qué presuntos ideales la televisión va más allá de los límites de sus propias ideas, señor Presidente, más allá de los límites de su propia moral. Otra vez, señor Presidente, como decían los escolásticos, usted no quiere el mal, pero lo consiente. (Rumores) $)^{137}$

136 Quintana, 2007, pp. 205-206.

137 Calvo-Sotelo, 1990, p. 254. 
En definitiva, la batalla por la televisión (pública y privada) durante el mandato de Calvo-Sotelo se convirtió en crisol de todas las tensiones políticas y mediáticas de la época. La debilidad del presidente (dentro y fuera de UCD), su indecisión en ocasiones y sus equivocaciones en otras, determinaron que la pequeña pantalla desempeñara un papel esencial en la crisis de UCD. Del mismo modo que RTVE había servido para encumbrar el liderazgo de Suárez, no es exagerado señalar que contribuyó de forma importante al desgaste de Calvo-Sotelo.

\section{Fuentes}

Archivo personal de Leopoldo Calvo-Sotelo Archivo José Pedro Pérez Llorca, Archivo General de la Universidad de Navarra Archivo personal José Antonio Pérez González

Colección Diario 16, Hemeroteca Universidad Autónoma de Barcelona

Entrevista Matías Rodríguez Inciarte (29-5-2018)

Entrevista Eugenio Nasarre (12-9-2018)

Hemeroteca on line El País

Hemeroteca on line $A B C$

\section{Bibliografía}

Alonso Castrillo, S., La apuesta del centro. Historia de la UCD, Alianza Editorial, Madrid, 1996.

ARIAS, I., Los presidentes y la diplomacia. Me acosté con Suárez y me levanté con Zapatero, Plaza \& Janés, Barcelona, 2012.

AtTARD, E., Vida y muerte de UCD, Planeta, Barcelona, 1983.

BARRera, C., Historia del proceso democrático en España: tardofranquismo, transición y democracia, Fragua, Madrid, 2002.

Bustamante, E., Radio y televisión en España. Historia de una asignatura pendiente de la democracia, Gedisa, Barcelona, 2006.

Calvo-Sotelo, L., Memoria viva de la Transición, Plaza \& Janés y Cambio 16. Barcelona, 1990.

Calvo-Sotelo Ibáñez-Martín, P., Leopoldo Calvo-Sotelo. Un retrato intelectual, Fundación Ortega-Marañón y Marcial Pons, Madrid, 2010.

CASTEDO, F., «El camino hacia una televisión auténtica» en VVAA: Historia de la transición. 10 años que cambiaron España (1973-1983), Diario 16, Madrid, 1984, pp. 711-12 
DíEz Miguel, D., Adolfo Suárez y el CDS (1982-1996), Tesis doctoral inédita, Universidad de Valladolid, 2017.

Feo, J. , Aquellos años, Ediciones B, Barcelona, 1993.

FraGa, M., En busca del tiempo servido, Planeta Barcelona, 1987.

Guerra, A., Cuando el tiempo nos alcanza, Espasa, Madrid, 2007.

Herrero de Miñón, M., Memorias de estío, Ediciones Temas de Hoy, Madrid, 1993.

Hopkin, J., El partido de la Transición. Ascenso y caída de UCD, Acento, Madrid, 2000.

Hunneus, C., La Unión de Centro Democrático y la transición a la democracia en España, CIS, Madrid, 1985.

LÓPEZ DE CELIS, M. Á., Las damas de la Moncloa. Retrato íntimo de seis mujeres que ya forman parte de nuestra historia, Espasa, Barcelona, 2013.

Montero DíAz, J. (dir.), Una televisión con dos cadenas. La programación en España (1956-1990), Cátedra, Madrid, 2018.

MARTín Jiménez, V., Televisión española y la Transición democrática. La comunicación política del Cambio (1976-1979), Universidad de Valladolid, Valladolid, 2013.

Munsó CABús, J., La otra cara de la televisión (45 años de historia y política audiovisual), Flor del Viento, Barcelona, 2001.

NAsArre, E., «El fracaso del estatuto» en VVAA: Historia de la transición. 10 años que cambiaron España (1973-1983), Diario 16, Madrid, 1984, p. 715.

Palacio, M., La televisión durante la Transición española, Cátedra, Madrid, 2012.

Pelaz LóPez, J.V., «El Candidato. La imagen pública de Leopoldo Calvo-Sotelo en vísperas de su investidura en 1981» en GonZÁleZ, R.M y otros (Dirs.), Historia, Periodismo y Comunicación, Estudios en homenaje al profesor Celso Almuiña Fernández, Universidad Valladolid, 2016, pp. 457-470.

Pelaz López, J.V. y Díaz Miguel, D., «El gobierno de Leopoldo Calvo-Sotelo o el eslabón perdido de la Transición» en Ayer 109 (1), 2018, pp. 325-348.

Pérez Herrera, G., Trayectoria política de José Pedro Pérez Llorca, Tesis doctoral inédita, Universidad de Navarra, 2017.

PÉREZ ORNIA, J.R., La televisión y los socialistas. Actividades del PSOE respecto a TVE durante la Transición (1976-1981), Universidad Complutense, Madrid, 1988.

Powell, C., España en democracia, 1975-2000. Las claves de la profunda transformación de España, Plaza \& Janés, Barcelona, 2002.

Quintana Paz, N., Televisión y prensa durante la UCD. Premios y castigos mediático-gubernamentales, Fragua, Madrid, 2007.

Robles PIQUeR, C., «Una etapa difícil» en VVAA. Historia de la transición. 10 años que cambiaron España (1973-1983), Diario 16, Madrid, 1984, p. 713.

- Memoria de cuatro Españas. República, guerra, franquismo y democracia, Planeta, Barcelona, 2011. 
Rodríguez InCIARTE, M., «Crónica de dos intentos frustrados» en VVAA. Historia de la Transición. 10 años que cambiaron España (1973-1983), Diario 16, Madrid, 1984, pp. 719-721.

Rueda LafFond, JC. y Chicharro Merayo, M.M., La televisión en España (1967-2006). Política, consumo y cultura televisiva, Editorial Fragua, Madrid, 2006.

Sinova, J., La gran mentira. El tinglado de la televisión al descubierto. Planeta. Barcelona, 1983.

Soto, A., Transición y cambio en España, 1975-1996. Alianza Editorial, Madrid, 2005.

Sotillos, E., 1982. El año clave, Aguilar, Madrid, 2002.

\section{Financiación y Agradecimientos}

Este trabajo se realiza en el marco del Proyecto de Investigación: «Perfiles del centro político (1976-1986): proyectos y realizaciones» HAR 2016-75600-C2-2-P (AEI/FEDER, UE).

Una vez más agradezco a la familia Calvo-Sotelo las facilidades prestadas para el desarrollo de esta investigación.

\section{Datos del Autor}

José-Vidal Pelaz López. Profesor Titular de Historia Contemporánea en la Facultad de Filosofía y Letras de la Universidad de Valladolid. Coordinador del Máster "Europa y el Mundo atlántico: poder, cultura y sociedad» impartido por la UVa y la UPV/EHU.

Entre sus líneas de investigación preferentes destacan la Historia de la comunicación social y la Historia política reciente, tanto española como universal. En relación a la primera podemos citar sus libros Caciques, apóstoles y periodistas. Medios de comunicación, poder y sociedad en Palencia (1898-1939)(2000) y Ver cine. Los públicos cinematográficos en el siglo XX (2002). Respecto a la historia reciente de España ha publicado El Estado de las Autonomías. Nacionalismos y regionalismos en la Historia Contemporánea de España (2002), y El Estado y las Autonomías. Treinta años después (2011).

También es autor de una biografía de Winston Churchill (2012), y coautor de una Historia del Mundo actual (3. ${ }^{\circ}$ ed. 2006). Asimismo ha publicado numerosos capítulos de libros y artículos en revistas especializadas. En la actualidad investiga sobre el gobierno de Leopoldo Calvo-Sotelo (1981-1982) en el marco del Proyecto: "Perfiles del centro político (1976-1986): proyectos y realizaciones», del cual es Investigador Principal 